\title{
Genetic Deletion of Paired Immunoglobulin-Like Receptor B Does Not Promote Axonal Plasticity or Functional Recovery after Traumatic Brain Injury
}

\author{
Shusaku Omoto, ${ }^{1,2}$ Masaki Ueno, ${ }^{1}$ Soichiro Mochio, ${ }^{2}$ Toshiyuki Takai, ${ }^{3,4}$ and Toshihide Yamashita ${ }^{1}$ \\ ${ }^{1}$ Department of Molecular Neuroscience, Graduate School of Medicine, Osaka University, Suita-shi, Osaka 565-0871, Japan, ${ }^{2}$ Department of Neurology, The \\ Jikei University School of Medicine, Minato-ku, Tokyo 105-8461, Japan, ${ }^{3}$ Department of Experimental Immunology and ${ }^{4}$ Core Research for Evolutional \\ Science and Technology Program of Japan Science and Technology Agency, Institute of Development, Aging, and Cancer, Tohoku University, Aoba-ku, \\ Sendai-shi, Miyagi 980-8575, Japan
}

The rewiring of neural networks is a fundamental step in recovering behavioral functions after brain injury. However, there is limited potential for axonal plasticity in the adult CNS. The myelin-associated proteins Nogo, myelin-associated glycoprotein (MAG), and oligodendrocyte myelin glycoprotein $(\mathrm{OMgp})$ are known to inhibit axonal plasticity, and thus targeting the inhibitory pathways they participate in is a potential means of promoting plasticity and functional recovery. Each of Nogo, MAG, and OMgp interacts with both the Nogo receptor (NgR) and paired immunoglobulin-like receptor B (PirB). Here, we determined whether blocking PirB activity enhances axonal reorganization and functional recovery after cortical injury. We found that axons of the contralesional corticospinal tract sprouted into the denervated side of the cervical spinal cord after unilateral injury of the motor cortex. The extent to which this axonal reorganization occurred was far greater in mice lesioned during early postnatal days than in mice lesioned at an age when myelin had begun to form. This suggests that myelin-associated proteins might limit axonal remodeling in vivo. However, the number of sprouting fibers within either the corticospinal or corticorubral tract was not enhanced in PirB ${ }^{-1-}$ mice. Blocking PirB signaling also failed to enhance functional recovery with three motor tests. Our results suggest that blocking the function of PirB is not sufficient to promote axonal reorganization or functional recovery after cortical injury.

\section{Introduction}

Brain injuries, such as traumatic injury or stroke, often lead to devastating motor deficits. For restoration of impaired functions after cortical damages, axonal reorganization, including spared corticofugal projections, is required in the compensation for lost neural networks (Nudo, 2006; Murphy and Corbett, 2009; Benowitz and Carmichael, 2010). However, in contrast to the developing CNS, the potential for axonal plasticity in the mature CNS is extremely limited. It has been believed that an inhibitory property of myelin is one of the main factors limiting axonal growth and plasticity (Yiu and $\mathrm{He}, 2006$ ). Three myelinassociated proteins have been identified as responsible for this inhibitory property: Nogo, myelin-associated glycoprotein (MAG), and oligodendrocyte myelin glycoprotein (OMgp) (Yamashita et al., 2005; Giger et al., 2008). The inhibition of axonal growth by these proteins is mediated via the Nogo receptor (NgR) (Fournier et al., 2001; Domeniconi et al., 2002; Liu et

\section{Received June 22, 2010; accepted July 26, 2010}

This work was supported by a Grant-in-Aid for Young Scientists (S) from Japan Society for the Promotion of Science. We thank Yuka Nakamura, Yuki Fujita, and Sachiko Lee for the helpful advice and technical support they provided during the course of this study.

Correspondence should be addressed to Toshihide Yamashita, Department of Molecular Neuroscience, Graduate School of Medicine, Osaka University, 2-2 Yamadaoka, Suita-shi, 0saka 565-0871, Japan. E-mail: yamashita@ molneu.med.osaka-u.ac.jp.

DOI:10.1523/JNEUROSCI.3228-10.2010

Copyright $\odot 2010$ the authors $\quad 0270-6474 / 10 / 3013045-08 \$ 15.00 / 0$ al., 2002; Wang et al., 2002). A number of studies have demonstrated enhanced axonal growth and plasticity after CNS injury by targeting NgR, e.g., after spinal cord injury (GrandPré et al., 2002; Li and Strittmatter, 2003; Li et al., 2004, 2005) or cortical injury (Lee et al., 2004). However, despite this evidence, the function of $\mathrm{NgR}$ in vivo remains controversial. Indeed, two studies failed to show regeneration of corticospinal tract (CST) after spinal cord injury in NgR null mice (Kim et al., 2004; Zheng et al., 2005). These observations suggest that there is another receptor for the myelin-associated proteins.

It was recently reported that the paired immunoglobulin-like receptor (PirB) is a high-affinity receptor for Nogo, MAG, and OMgp (Atwal et al., 2008). Besides an involvement of PirB in restricting ocular dominance plasticity in the postnatal brain (Syken et al., 2006), Atwal et al. (2008) clearly demonstrated that a loss of PirB function partially reversed the inhibition of neurite outgrowth produced by myelin-associated proteins in vitro. These results suggest that PirB might contribute to the inhibition of axonal plasticity by myelin in vivo. If so, PirB might be an attractive target of therapies aiming to enhance axonal plasticity after brain injury. However, it remains to be shown whether inhibition of PirB signaling does indeed facilitate the recovery from injury in vivo.

In the present study, we aimed to reveal whether blocking the function of PirB enhances axonal remodeling and functional recovery after cortical injury. We focused on the newly sprout- 
ing axons from the corticorubral tract (CRT) and the CST, originated from the contralesional motor cortex and suggested to contribute to functional recovery (Chen et al., 2002; Lee et al., 2004; Takahashi et al., 2009; Benowitz and Carmichael, 2010). We assessed the remodeling of these motor tracts and the functioning of an impaired forelimb following a unilateral injury in the motor cortex of PirB ${ }^{-1-}$ mice.

\section{Materials and Methods}

Mice. Postnatal and adult C57BL/6J mice (male, wild type) were purchased from Charles River Japan. C57BL/6 strain mice deficient in PirB (PirB ${ }^{-1-}$ mice) have been described previously (Ujike et al., 2002). The sequences encoding the ectodomain and juxtamembrane domains of PirB were deleted to create $\mathrm{PirB}^{-1-}$ mice. All experimental procedures were approved by the institutional committee of Osaka University.

Unilateral cortical ablation in developing mice. Unilateral lesions of the primary motor cortex were induced in postnatal [postnatal day 3 (P3), $n=5 ; \mathrm{P} 9, n=6 ; \mathrm{P} 15, n=6 ; \mathrm{P} 21, n=5$ ] and adult ( 8 weeks old, $n=5$ ) mice. Three-day-old mice were anesthetized on ice and older mice anesthetized with sodium pentobarbital $(50 \mathrm{mg} / \mathrm{kg}$, i.p.; Somnopentyl, Kyoritsu Shoji). The skull was exposed with a midline skin incision and bone overlying the left sensorimotor cortex area removed. Cortical ablation (depth: $0.7 \mathrm{~mm}$ in P3 mice; $1.0 \mathrm{~mm}$ in older mice) was performed by aspiration with a pipette. The wound was sutured and pups were returned to their mother. Sham-operated mice (in age groups the same as those of lesioned mice, $n=5$ in each) underwent the same surgical procedures except for cortical ablation.

Traumatic cortical injury in PirB ${ }^{-1-}$ and wild-type mice. $\mathrm{PirB}^{-1-}$ and wild-type adult mice (male, 8 weeks old, $n=9$ for each) were used. The mice were anesthetized with sodium pentobarbital and stabilized in a stereotaxic frame (Muromachi). The scalp was retracted and a $4 \mathrm{~mm}$ diameter circular craniotomy performed with a drill on the left side, with the center at $0 \mathrm{~mm}$ anteroposterior and $2 \mathrm{~mm}$ lateral to the bregma. A controlled cortical impact was made using a Pneumatic Impact Device (Amscien Instruments) with a $3.0 \mathrm{~mm}$ flat-tip diameter, as described previously (Onyszchuk et al., 2007). The impact was made at a depth of $1.0 \mathrm{~mm}$ and a speed of $4.0-4.5 \mathrm{~m} / \mathrm{s}$. The scalp was then sutured and closed and the mice left to wake from the anesthesia.

Anterograde labeling of the corticofugal projections. Two weeks after the cortical lesion or sham operation, mice were anesthetized (as above) and placed on a stereotaxic frame. The skull overlying the right primary motor cortex was carefully removed with a drill. To visualize the uninjured CST and CRT, the anterograde tracer biotinylated dextran amine (BDA) (molecular weight, 10,000; dilution, 10\% in PBS; Invitrogen) was injected at 4 sites $(0.4 \mu \mathrm{l} / \mathrm{site})$ within the forelimb motor area, as guided by a functional map of the motor cortex (Pronichev and Lenkov, 1998).

Retrograde labeling of corticospinal and rubrospinal neurons. Retrobeads (Lumafluor), a fluorescent retrograde tracer, was injected into the cervical spinal cord. Intact mice were anesthetized as described above and stabilized in a stereotaxic frame. A midline incision was made above the cervical spine and the paraspinal muscles parted to reveal its aspect. A laminectomy was then performed to expose the dorsal aspect of the C6 segment of the spinal cord. Retrobeads $(0.6 \mu \mathrm{l})$ was injected into the right side of the C6 spinal gray matter ( $0.7 \mathrm{~mm}$ lateral and $0.5 \mathrm{~mm}$ deep) using a glass capillary. The animals were killed $7 \mathrm{~d}$ later.

$B D A$ histochemistry and quantitative analysis of corticofugal projections. For the BDA tracing experiment, mice were killed 2 weeks after injection with BDA ( 4 weeks after cortical ablation, cortical impact, or sham operation). The mice were perfused transcardially with PBS followed by $4 \%$ paraformaldehyde in $0.1 \mathrm{~m}$ phosphate buffer. The brain and cervical spinal cord were dissected, postfixed in the same fixatives, and immersed overnight in PBS containing 30\% sucrose. The brain and cervical cord specimens $(\mathrm{C} 4-\mathrm{C} 7)$ were then embedded in Tissue-Tek OCT and kept frozen at $-80^{\circ} \mathrm{C}$ until use. Transverse sections (20 $\mu \mathrm{m}$ thick) were prepared using a cryostat. The sections were blocked for $4 \mathrm{~h}$ in PBS supplemented with $0.3 \%$ Triton X-100 and then incubated for $2 \mathrm{~h}$ with Alexa Fluor 488-conjugated streptavidin (1:400; Invitrogen) in PBS.
A
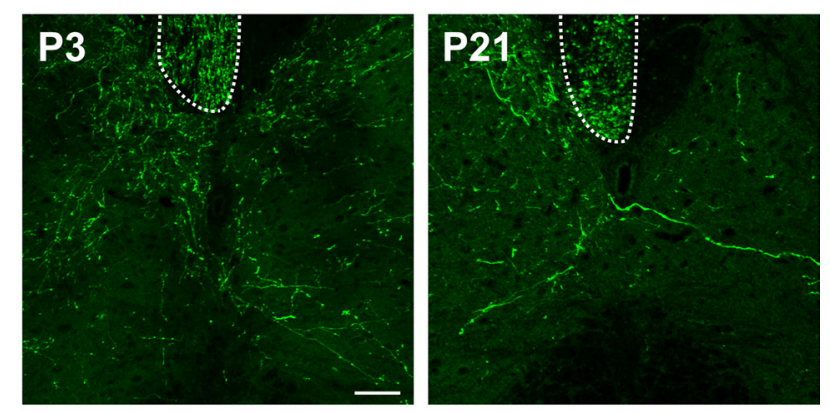

B

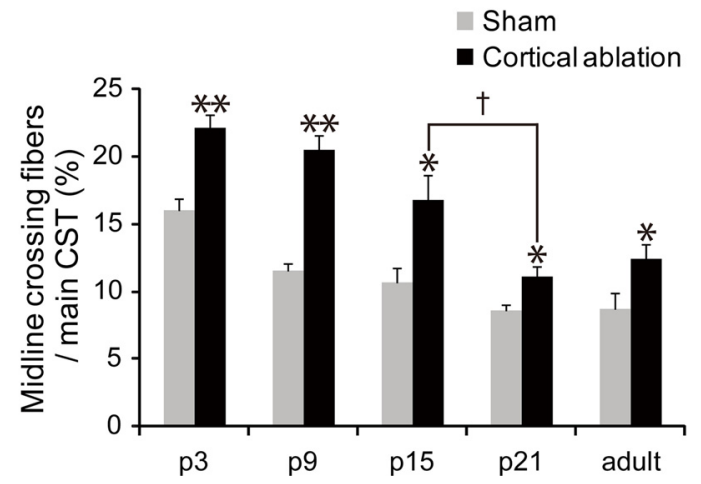

Figure 1. CST fibers crossed the midline of the spinal cord after cortical ablation in postnatal mice. $A$, Representative transverse sections of the cervical cord obtained 4 weeks after cortical ablation done on P3 and P21. BDA was injected into the contralesional motor cortex 2 weeks after the ablation. Numerous sprouting axons from the intact CST (BDA, green) crossed the midline into the denervated side of the cervical cord. More axons crossed the midline in mice lesioned on P3 than in mice lesioned on P21. Dotted lines indicate histochemically labeled dorsal CST. Scale bar, $50 \mu \mathrm{m}$. $\boldsymbol{B}$, The number of BDA-positive axons crossing the cervical cord (C4 -C7) midline in postnatal and adult mice, normalized by the total number of labeled dorsal CST fibers. The ages shown are when the lesions were made. Cortical ablation significantly increased the number of midline-crossing fibers in all age groups. However, the extent of this effect was reduced for lesions made on or later than P21. Data are presented as mean \pm SEM. ${ }^{* *} p<0.01 ;{ }^{*} p<0.05$ versus sham operation in similarly aged mice; ${ }^{\dagger} p<0.05$ for $\mathrm{P} 15$ lesion versus $\mathrm{P} 21$ lesion.

Corticofugal projections from the uninjured primary motor cortex to the denervated gray matter in the cervical cord were quantitatively analyzed with fluorescence microscopy (Olympus BX51) at a magnification of $400 \times$. We counted the number of BDA-positive fibers that crossed the midline at the $\mathrm{C} 4-\mathrm{C} 7$ levels in 10 (mice with cortical ablation) or 20 (mice with traumatic injury) sections for each vertebral level (40 or 80 sections in total, respectively). We also analyzed corticofugal projections to the contralateral red nucleus in mice with traumatic injury: BDApositive fibers crossing the midline at the level of the red nucleus were counted in each of 10 sequential sections for each mouse. To normalize interanimal differences in tracing, the number of fibers crossing the midline was divided by the total number of labeled dorsal CST fibers (Thallmair et al., 1998). The number of BDA-positive fibers in the dorsal CST was determined from images captured by a laserscanning confocal microscope (Olympus FV-1000) using ImageJ software (NIH).

Quantification of lesion volume. For the assessment of brain lesion volume, coronal sections ( $40 \mu \mathrm{m}$ thick) of the brain were stained with cresyl violet (Nissl stain; Sigma). The area of lost tissue in each of 5-7 sections (spaced $0.5 \mathrm{~mm}$ apart) was measured using Photoshop software (Adobe Systems) and the total lesion volume calculated as described previously (Onyszchuk et al., 2007).

Tissue staining. For immunostaining of MAG, myelin basic protein (MBP), PirB, and protein kinase $\mathrm{C} \gamma(\mathrm{PKC} \gamma)$, sections ( $20 \mu \mathrm{m}$ thick) were blocked with $5 \%$ bovine serum albumin (BSA; Sigma) and $0.1 \%$ Triton X-100 in PBS and incubated with mouse anti-MAG (1:200, Millipore 

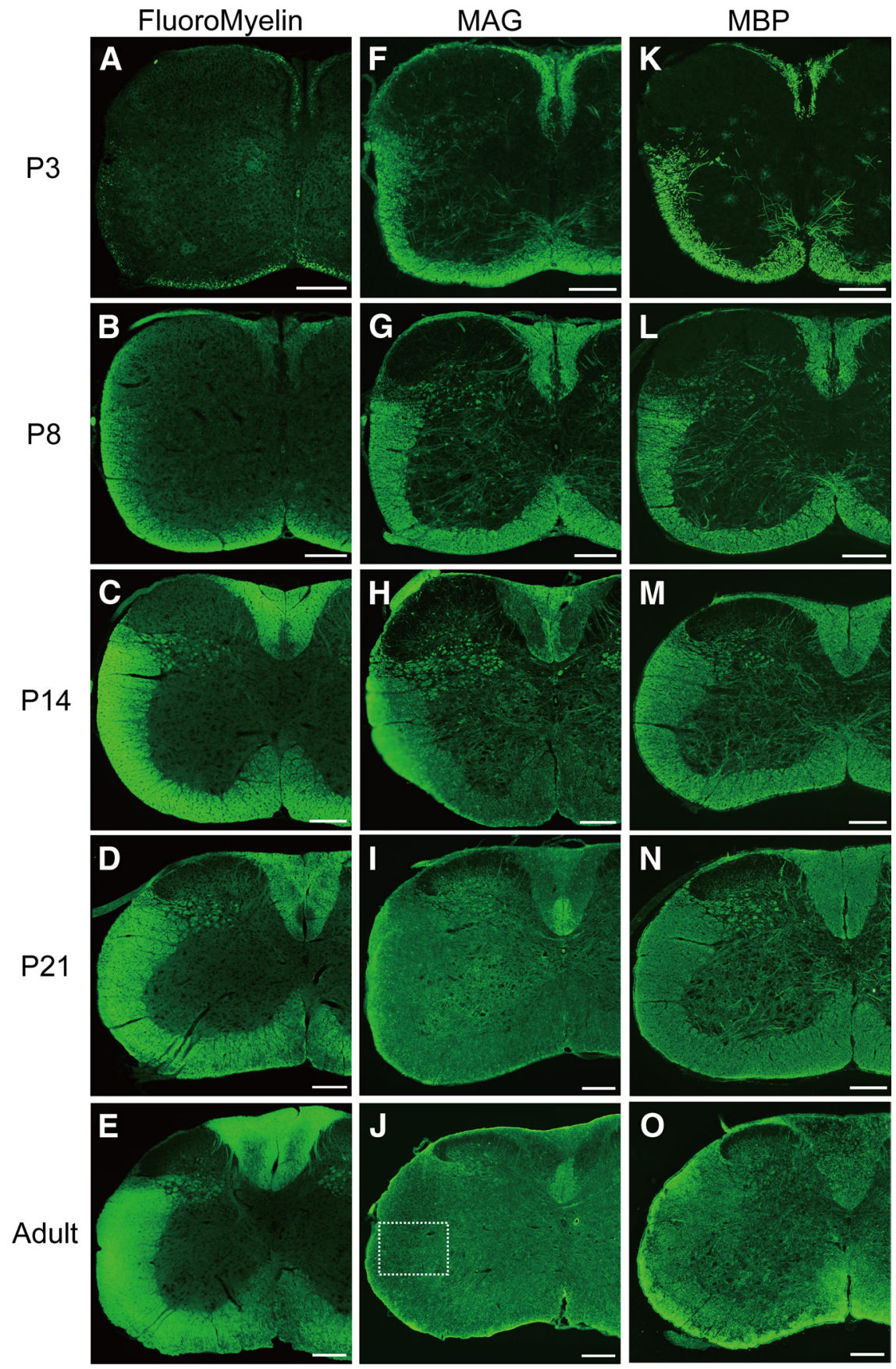

Figure 2. Myelin formation in the cervical cord of postnatal and adult mice. $A-E$, Postnatal and adult spinal cord stained with FluoroMyelin. Myelin was not detectable at P3 $(\boldsymbol{A})$ but had appeared in the white matter by $\mathrm{P} 8(\boldsymbol{B})$. There was then a rapid progression of myelination to P14 and beyond, mainly in the white matter $(\boldsymbol{C}-\boldsymbol{E}) . \boldsymbol{F}-\boldsymbol{J}$, Expression of MAG in the postnatal and adult spinal cord. At P3, MAG was detectable in both white and gray matter, but at quite low levels in the latter and dorsal CST (F). By P8, MAG expression had increased in the gray matter, albeit in a sparse pattern, but not in the dorsal CST (G). MAG expression appeared in the dorsal CST at P14 $(\boldsymbol{H})$. MAG expression was observed intensely in the white and gray matter at P21 and in the adult $(\boldsymbol{I}, \boldsymbol{J})$. $\boldsymbol{K}-\boldsymbol{O}$, Expression of MBP in the postnatal and adult spinal cord. The expression patterns are similar to that of MAG $(\boldsymbol{F}-\boldsymbol{J})$. Highmagnification image of the dotted square in $J$ is shown in supplemental Figure 1 (available at www.jneurosci.org as supplemental material). Scale bars, $200 \mu \mathrm{m}$.

Bioscience Research Reagents), rat anti-MBP (1:100, Abcam), rat anti$\operatorname{PirB}(5 \mu \mathrm{g} / \mathrm{ml}, \mathrm{R} \& D$ Systems), or rabbit anti-PKC $\gamma(1: 500$, Santa Cruz Biotechnology) antibodies overnight at $4^{\circ} \mathrm{C}$. As the secondary antibodies, Alexa 488 anti-mouse IgG (1:500, Invitrogen), Alexa 488 or 568 anti-rat $\operatorname{IgG}(1: 500$, Invitrogen), and Alexa 568 anti-rabbit IgG (1:500, Invitrogen) were used. For the staining of myelin, unblocked tissue sections were incubated with FluoroMyelin Green (1:300, Invitrogen) (Wu et al.,
2006) for $20 \mathrm{~min}$. Images were acquired using a laser-scanning confocal microscope (Olympus FV-1000) or fluorescence microscopy (Olympus BX51).

Behavioral tests. Affected forelimb use was assessed using cylinder, staircase, and gridwalking tests. The cylinder test evaluates forelimb use during spontaneous vertical exploration within a cylinder (Baskin et al., 2003; Starkey et al., 2005). Mice were placed in a cylinder ( $9 \mathrm{~cm}$ in diameter and $15 \mathrm{~cm}$ high) and recorded with a video camera. We counted the number of contacts with the cylinder wall made during a full rear by the left and right forelimbs independently and by both forelimbs simultaneously. During a rear, if immediately after simultaneous contact one forelimb (e.g., the right forelimb) made several contacts or dropped, both "both" and "left" were recorded. A total of 20 movements were recorded. Cylinder test performance was scored as (impaired right forelimb use + both forelimbs use)/total use. The cylinder test does not require pretraining but was performed once by each animal before surgery to obtain a baseline score.

The staircase test assesses skilled forepaw use (Montoya et al., 1991; Baird et al., 2001; Starkey et al., 2005). Food was restricted overnight before the morning on which the test was performed. Mice were placed in a staircase apparatus (Melquest) in which two food pellets $(6-10 \mathrm{mg})$ had been placed on each step of the stair (eight steps/side). Each testing period lasted $30 \mathrm{~min}$ and the total number of pellets retrieved with the affected right forepaw was counted. Mice were trained for $10 \mathrm{~d}$ before receiving their injury and those that could not retrieve five pellets were excluded from the experiments.

The grid-walking test assesses the ability to accurately place the forepaws on the rungs of a grid during spontaneous exploration (Zhang et al., 2002; Starkey et al., 2005). Mice were placed on a wire grid $(200 \times 240 \mathrm{~mm})$ with $12 \mathrm{~mm}$ square holes and allowed to freely explore for 3 min. Performance was recorded with a video camera. The number of footslips of the impaired right forepaw was assessed as a percentage of the first 50 steps. A footslip was scored either when the paw completely missed a rung (in which case the limb fell between rungs and the animal lost balance) or when the paw was correctly placed on a rung but slipped off when bearing body weight. Pretraining on the gridwalking test is not necessary, but each animal was tested once before surgery to obtain a baseline score.

Statistics. All data are presented as mean \pm SEM. The number of midline-crossing fibers was compared between cortical ablation and sham-operated mice using one-way ANOVA followed by post hoc Tukey-Kramer (for age group comparisons) and Student's $t$ (ablation vs sham within each age group) tests. Differences in midline sproutingfiber numbers and lesion volumes between the wild-type and PirB ${ }^{-1-}$ trauma-injury mice were investigated using Student's $t$ test. All behavioral data were compared using repeated-measure ANOVA followed by a post hoc Tukey-Kramer test. A $p$ value of $<0.05$ was considered statistically significant. 
Motor cortex
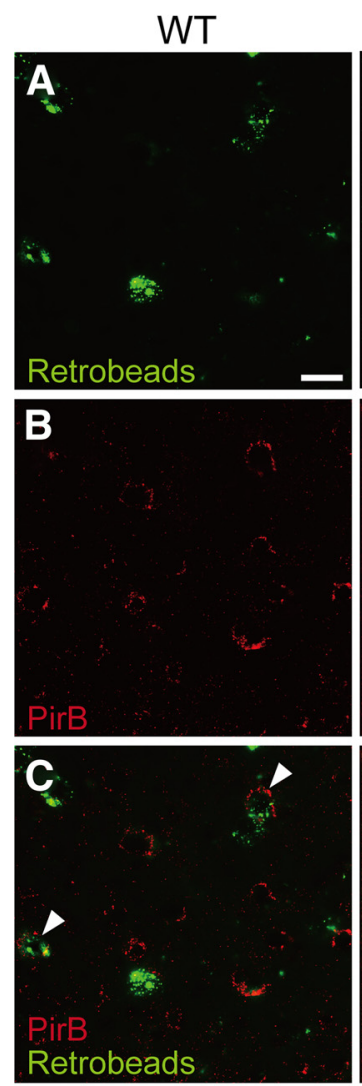

PirB -/-
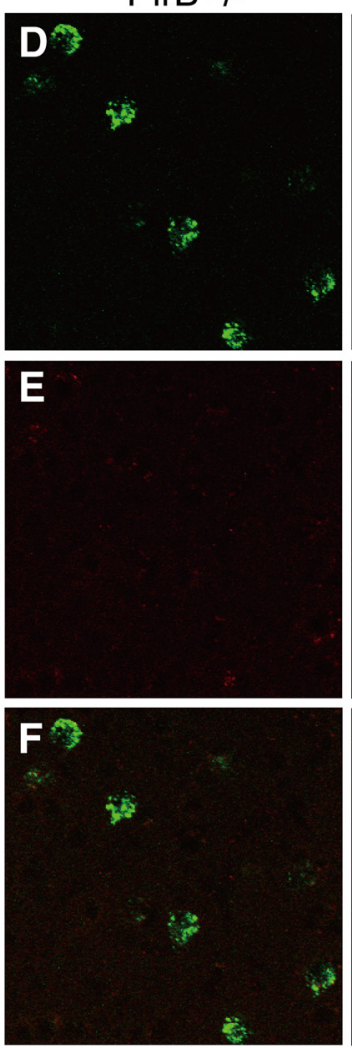

Red nucleus
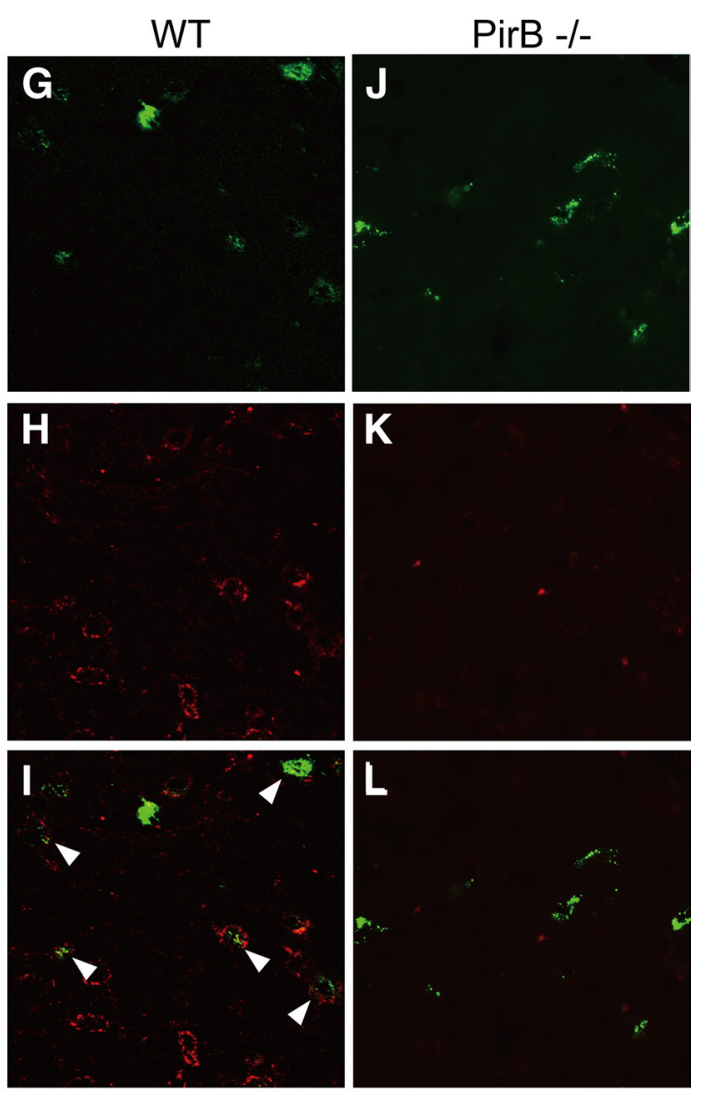

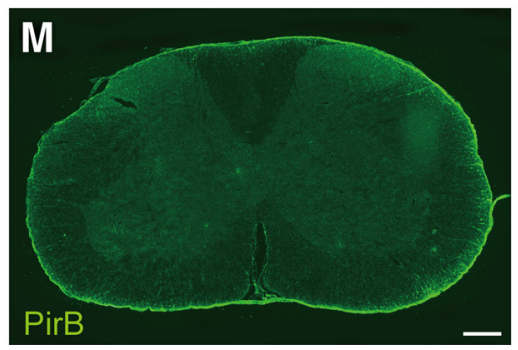

Figure 3. Expression of PirB in corticospinal and rubrospinal neurons. $\boldsymbol{A}-\boldsymbol{L}$, Retrobeads was injected into the spinal cord at $C 6$. Coronal sections of contralateral motor cortex $(\boldsymbol{A}-\boldsymbol{F})$ and midbrain at the level of the red nucleus $(\boldsymbol{G}-\boldsymbol{L})$ in wild-type $(\boldsymbol{A}-\boldsymbol{C}$ and $\mathbf{G}-\boldsymbol{I})$ and $\operatorname{PirB}^{-1-}$ mice $(\boldsymbol{D}-\boldsymbol{F}$ and $\boldsymbol{J}-\boldsymbol{L})$ are shown. Corticospinal $(\boldsymbol{A}, \boldsymbol{D})$ and rubrospinal $(\boldsymbol{G}, \boldsymbol{J})$ neurons were labeled with Retrobeads (green). In wild-type mice, PirB (red) was expressed in layer V motor cortex neurons $(\boldsymbol{B})$ and in the magnocellular region of the red nucleus $(\boldsymbol{H})$. Merged images $(\boldsymbol{C}, \boldsymbol{I})$ show the colocalization of Retrobeads and PirB (arrowheads). In PirB ${ }^{-1-}$ mice, PirB expression was undetectable in either region $(\boldsymbol{E}, \boldsymbol{F}, \boldsymbol{K}$, and $\boldsymbol{L})$. Scale bar, $20 \mu \mathrm{m} . \boldsymbol{M}$, Transverse section of the cervical cord stained for PirB from wild-type adult mice. PirB was not detected in the cervical spinal cord. Scale bar, $200 \mu \mathrm{m}$.

\section{Results}

An association between myelin levels and axonal reorganization after cortical injury

Compared to neural circuits in the mature CNS, it is considered that those in the developing CNS have a much greater potential for plasticity due to immature myelin formation (Schwab and Bartholdi, 1996). However, there are no reports showing how myelin formation relates to axonal reorganization after cortical injury at different stages of development. In the first of our experiments, we examined compensatory axonal sprouting of intact CST fibers after unilateral ablation of the motor cortex in variously aged postnatal (P3, P9, P15, and P21) and adult (8 weeks old) mice. The intact CST was labeled by injecting the anterograde tracer BDA into the contralesional motor cortex. We found remarkable levels of axonal arbor sprouting into the denervated side of cervical cord gray matter 4 weeks after the cortical lesion was produced (Fig. $1 A$ ). For all age groups, the number of axons crossing the midline was significantly greater in lesioned mice than in sham-operated mice (Fig. $1 B)(p<0.01$ for P3 and P9 mice, $p<0.05$ for all older groups). The extent of CST reorganization was high if mice were lesioned at or before $\mathrm{P} 15$ but declined if they were lesioned thereafter (Fig. $1 B)(p<0.05$ for P15 vs P21).

We next investigated myelin formation in the postnatal spinal cord to reveal the relationship between myelin formation and CST reorganization across different stages of development. FluoroMyelin was used to visualize myelin. Myelin was not detectable at P3 (Fig. 2A) but was present in the white matter at P8 (Fig. $2 B)$. Compared to other regions in which white matter develops, myelination was delayed in the dorsal funiculus, where the main CST located, first appearing at P14 (Fig. 2C-E). We then examined the expression of two myelin-related proteins, MAG and MBP. MAG was detectable in both white and gray matter at P3 (Fig. $2 F$ ), but its expression was quite low in gray matter and the 
A

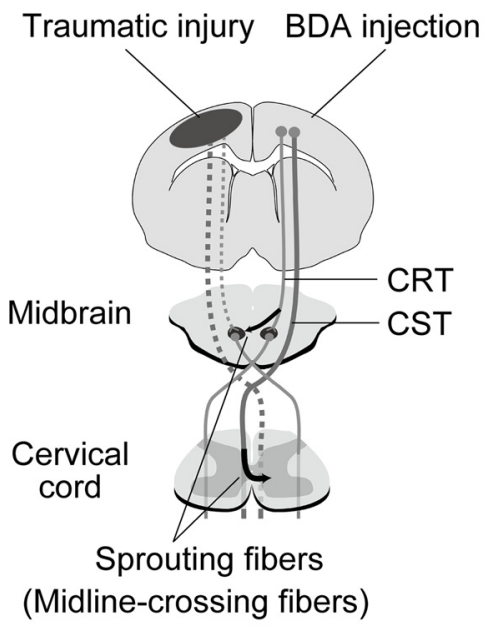

B

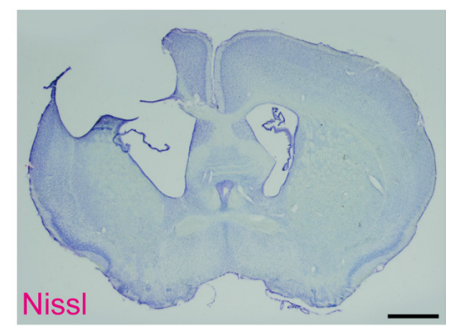

C
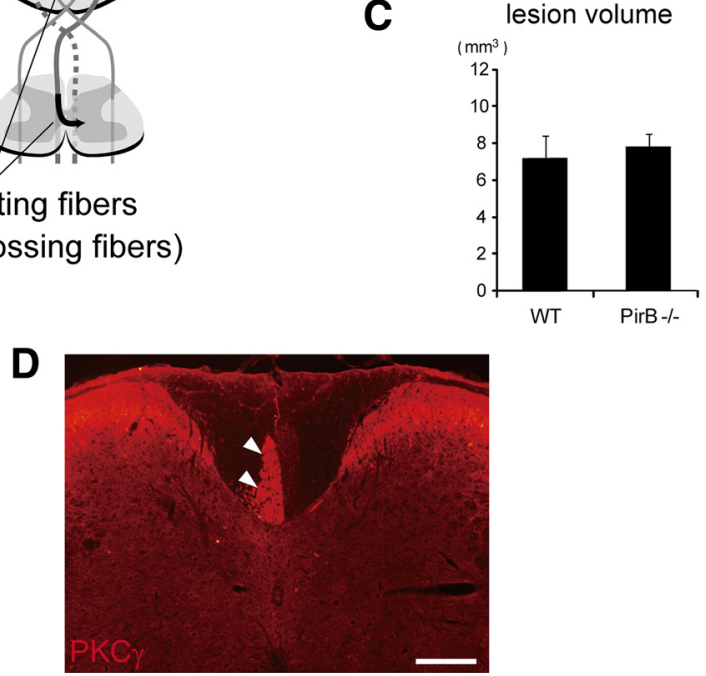

Figure 4. Traumatic cortical injury in wild-type and PirB ${ }^{-1-}$ mice. $A$, Schematic illustration of corticofugal projections from the primary motor cortex and the experimental procedures. Traumatic injury to the sensorimotor cortex disrupted both the CST and CRT (dotted lines). BDA was injected into the contralesional motor cortex 2 weeks after the injury. The black arrow shows axons of the intact CST or CRT sprouting and crossing the midline into the denervated side. $\boldsymbol{B}$, Representative Nissl-stained coronal sections of brain injured by a pneumatic impactor. Sensorimotor cortex was specifically destroyed. Scale bar, $1 \mathrm{~cm}$. $\boldsymbol{C}$, Measurement of lesion volume in wild-type and PirB ${ }^{-1-}$ mice. There were no significant differences between the groups. D, Immunostaining for PKC $\gamma$ in the cervical spinal cord at 1 week after the cortical injury. PKC $\gamma$ immunoreactivity completely disappeared in the right dorsal CST originating from the injured motor cortex. Arrowheads indicate the left intact CST from the uninjured motor cortex. Scale bar, $200 \mu \mathrm{m}$.

dorsal funiculus. MAG expression had increased in the gray matter by P8 but was sparse, with there being a pattern of MAGnegative areas (Fig. 2G). MAG expression in the dorsal funiculus had increased by P14 (Fig. $2 H$ ). There was then a rapid progression of MAG expression in the gray matter by P21 (Fig. 2I). In adult mice, there was a prominent and dense expression of MAG observed in both gray and white matter (Fig. 2J; supplemental Fig. S1, available at www.jneurosci.org as supplemental material). MBP immunostaining exhibited broadly similar expression pattern in development with MAG (Fig. $2 \mathrm{~K}-\mathrm{O}$ ). These results are consistent with the hypothesis that axonal plasticity was high during periods in which myelin formation was immature. Thus, it is conceivable that myelin-associated axonal growth inhibitors may limit axonal plasticity after cortical injury in adulthood, although several other factors, such as the cell-intrinsic mechanisms, might also contribute to the limitation of axonal plasticity (Benowitz and Carmichael, 2010; Sun and He, 2010).

\section{PirB expressed in corticospinal and rubrospinal neurons}

The presumption that myelin-associated proteins inhibit axonal reorganization after cortical injury prompted us to investigate whether blocking these inhibitory signals by blocking PirB activity enhances axonal plasticity and functional recovery. We first examined PirB expression in corticospinal and rubrospinal neu- rons, which regulate motor function. Retrobeads was injected into the cervical cord at $\mathrm{C} 6$ and labeled corticospinal neurons in layer $\mathrm{V}$ of the motor cortex (Fig. $3 A, D$ ) and rubrospinal neurons in the magnocellular part of the red nucleus (Fig. $3 G, J$ ). In wild-type mice, neurons in both of these regions were found with immunostaining to express PirB (Fig. $3 B, H$ ). In merged images of those, expression of PirB was found in most of the Retrobeadslabeled rubrospinal neurons (Fig. 3I) but only a small population of Retrobeadslabeled corticospinal neurons (Fig. 3C). In $\mathrm{PirB}^{-/-}$mice, we found no detectable signals of PirB in either region (Fig. $3 E, F, K, L)$. We further investigated the expression of PirB in the adult spinal cord. However, PirB expression was undetectable in either white or gray matter of wildtype mice (Fig. 3M).

\section{Axonal sprouting in the CST and CRT after traumatic cortical injury was not enhanced in $\mathrm{PirB}^{-1-}$ mice}

We tested the effect of blocking PirB activity on axonal reorganization and functional recovery after traumatic brain injury by delivering a controlled cortical impact to $\mathrm{PirB}^{-1-}$ mice (Fig. $4 A$ ). As shown in Figure $4 B$, there was complete destruction of the sensorimotor cortex 4 weeks after traumatic brain injury. There were no significant differences in brain lesion volume (determined from Nisslstained coronal brain sections) between the wild-type and PirB ${ }^{-/-}$mice (Fig. 4C). To determine whether the cortical impact led to a complete destruction of the CST, cervical spinal cord was stained with PKC $\gamma$, a marker of the CST, at 1 week after the injury (Bradbury et al., 2002). In sham control mice, PKC $\gamma$ immunoreactivity was present bilaterally in the dorsal CST of the cervical spinal cord (data not shown). In lesioned mice, $\mathrm{PKC} \gamma$ immunoreactivity disappeared in the right dorsal CST originating from the injured left motor cortex (Fig. 4D), which suggests that the cortical impact resulted in complete destruction of the CST.

Unilateral lesions of the motor cortex induce neuroanatomical changes in contralesional corticofugal projections, including the CST and CRT (Benowitz and Carmichael, 2010) (Fig. 4A). These newly formed neural circuits are highly correlated with functional recovery after cortical injury. Furthermore, using the present injury model, we recently found that axonal sprouting in the corticofugal tract helped form new neural networks that contributed to functional recovery after cortical injury (M. Ueno and T. Yamashita, unpublished data). We thus analyzed corticofugal projections that crossed the midline into the denervated side of the red nucleus (CRT) and cervical cord (CST) 4 weeks after injury in $\mathrm{PirB}^{-1-}$ mice. Prominent midline-crossing axons were observed after cortical destruction at the red nucleus (Fig. $5 A, C$ ) and cervical cord (Fig. $5 B, D$ ) level in both groups of mice, as observed after the injury by cortical ablation (Fig. 1). However, the number of midline-crossing axons did not differ significantly 
between $\mathrm{PirB}^{-1-}$ (Fig. 5C-F) and wild-type (Fig. 5A,B,E,F) mice. These results indicate that blocking PirB activity is not sufficient to promote axonal reorganization, at least in corticofugal projecting axons in vivo.

\section{Behavioral recovery after traumatic cortical injury was not enhanced in $\mathrm{PirB}^{-l-}$ mice}

We assessed the functional recovery of wild-type and PirB ${ }^{-1-}$ mice with three motor tests on the second postoperative day and then once a week for 4 weeks. The cylinder test was the first test used, and in which independent use of an affected forelimb to contact the interior cylinder wall during a rear is analyzed. On the second postoperative day, both groups showed marked deficits in contralesional right forelimb use (Fig. $6 \mathrm{~A}$ ). The frequency of impaired forelimb use gradually increased across the following 4 weeks, indicating a degree of recovery from the neurological deficit. However, there were no differences between the groups in the extent or speed of recovery. In the second motor test, the staircase test, food-restricted mice were placed in a staircase apparatus in which food pellets had been placed on each step. The number of food pellets retrieved with the impaired right forepaw was counted. On the second postoperative day, none of the mice in both of the groups performed well in retrieving pellets with the impaired forepaw (Fig. 6B). Performance gradually improved to some extent in both groups over the following 4 weeks, though there were no significant differences in the extent or speed of this improvement between the groups. In the third motor test, the grid-walking test, mice were placed on a wire grid with square holes and allowed to explore freely. We analyzed the percentage number of steps (out of 50) on which there was a footslip of the impaired right forepaw. On the second postoperative day, mice in both the groups showed marked deficits in their ability to accurately place the impaired forelimb, with the mean percentage of footslips being $\sim 17 \%$ (Fig. 6C). This percentage value gradually decreased over the following 4 weeks in both the groups. However, there were no differences between the groups in the extent of this recovery or the speed at which it occurred. The results of behavioral testing indicate that blocking PirB activity did not promote functional recovery.

\section{Discussion}

We found that the extent to which the intact CST sprouted into the denervated side of the cervical cord after unilateral cortical ablation was significantly less in mice lesioned on P21 than in mice lesioned on P15. This suggests that P15 or thereabouts marks the end of a critical period for CST plasticity, which tallies well with our finding that myelination of the CST and axons in the gray matter rapidly progressed after P14. Consistent with our observations, it has been reported that axonal sprouting after a unilateral CST lesion is relatively more extensive in myelin-free (neonatal X-irradiated) rats, in whom it occurs even if the lesion is made after P21 (Vanek et al., 1998). In terms of explaining the inverse relationship between myelin formation and axonal sprouting, we hypothesized that factors associated with myelin suppress plasticity. We tested this hypothesis by assessing the involvement of signals elicited by three myelin-associated axonal growth inhibitors in CST plasticity. However, we found that deletion of PirB did not enhance axonal reorganization in the CST or functional recovery
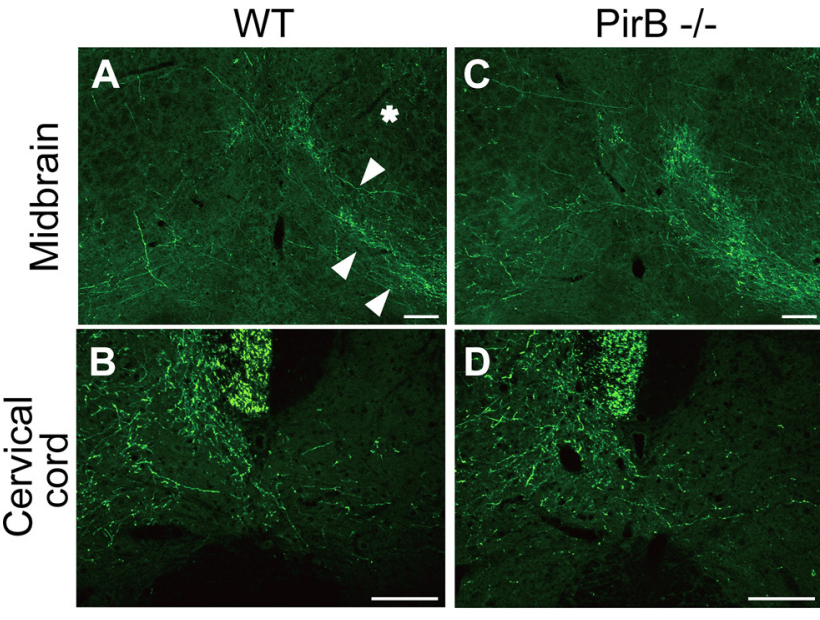

E

Midbrain
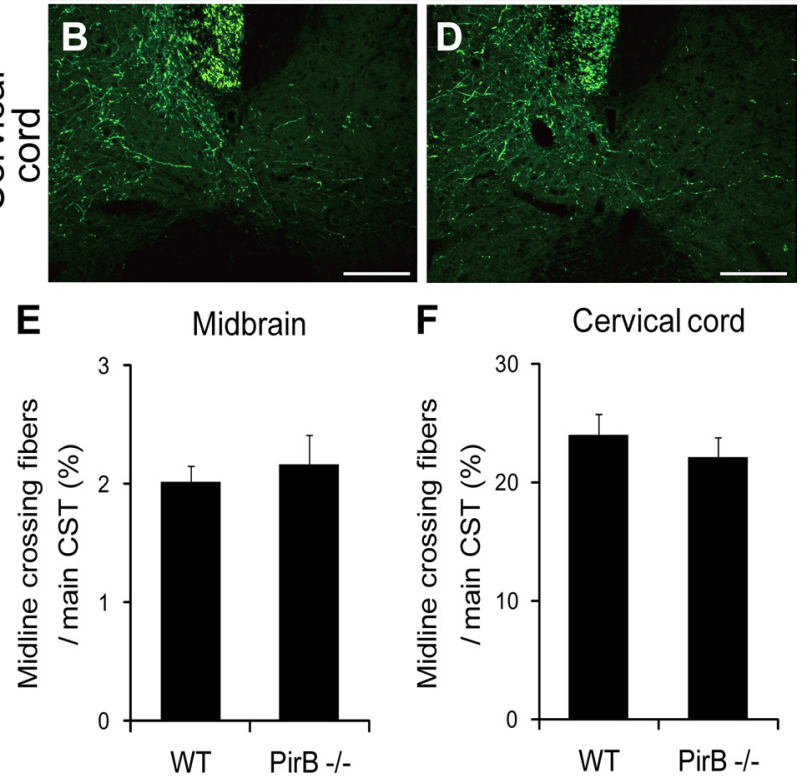

F

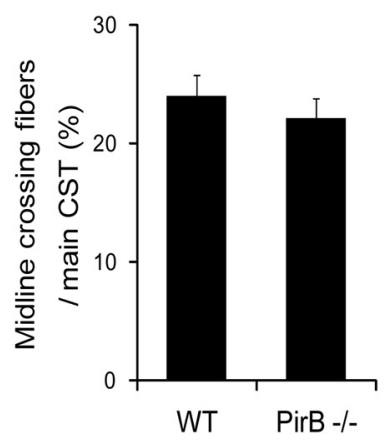

Figure 5. Axonal sprouting of the CRT and CST in wild-type and PirB ${ }^{-1-}$ mice. $A-D, B D A-$ labeled CRT or CST axons (green) traced from the contralesional motor cortex are shown in transverse sections at the level of the midbrain $(A, C)$ or cervical cord $(B, D)$, respectively. Robust midline-crossing axons were observed at both levels 4 weeks after injury in wild-type $(\boldsymbol{A}, \boldsymbol{B})$ and PirB $^{-1-}$ mice $(\boldsymbol{C}, \boldsymbol{D})$. The asterisk and arrowheads indicate the intact side of the red nucleus and CRT fibers, respectively. Scale bars, $100 \mu \mathrm{m} . \boldsymbol{E}, \boldsymbol{F}$, The number of axons crossing the midline in the midbrain $(\boldsymbol{E})$ or cervical cord $(C 4-C 7)(\boldsymbol{F}) 4$ weeks after injury, normalized by the total number of labeled dorsal CST fibers. Data are presented as mean \pm SEM. There were no significant differences between the groups at either the midbrain or cervical level.

Figure 6. Functional recovery of the impaired forelimb in wild-type and PirB ${ }^{-1-}$ mice. $\boldsymbol{A}$, Cylinder test. $\boldsymbol{B}$, Staircase test. $\boldsymbol{C}$, Grid-walking test. There were no significant differences in functional recovery from cortical injury between the groups on any tests.
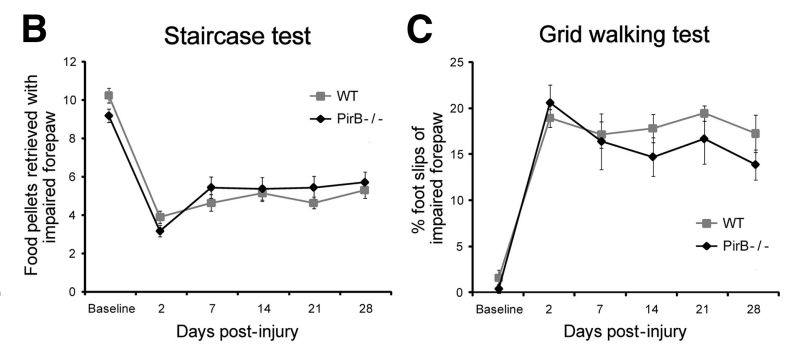

after cortical injury. This suggests that other inhibitory signals need to be blocked and/or growth-stimulating signals provided to promote axonal reorganization in the CNS. Some of the other inhibitory signals could involve MAG and an N-terminal region of NogoA, which can act through an integrin-related mechanism (Hu and Strittmatter, 2008). MAG also provides inhibitory signals via NgR2 and gangliosides (Schnaar and Lopez, 2009). There are further molecules that could inhibit axonal plasticity in the CNS. For example, each of ephrin-B3 (Benson et al., 2005), repulsive guidance molecule (RGM) (Hata et al., 2006), Sema4D/ CD100 (Moreau-Fauvarque et al., 2003), and netrin-1 (Löw et al., 
2008 ) is expressed in myelin and has been shown to inhibit axonal growth. Supporting this, disrupting the activity of repulsive guidance molecule (RGM) or the ephrin-B3 receptor EphA4 promoted axonal regeneration after spinal cord injury in vivo (Goldshmit et al., 2004; Hata et al., 2006).

A number of studies have shown that axonal sprouting after CNS lesions is more extensive during early postnatal days than during adulthood (Reinoso and Castro, 1989; Kuang and Kalil, 1990; Ono et al., 1990). Our results reveal that the potential for axonal sprouting declines with age on a time course parallel to that of myelination and MAG expression. The time course of myelination observed in the present study is consistent with the finding of a previous study using immunostaining for the major myelin components, including MBP, that myelin formation in the gray matter and the dorsal CST starts at around P11 in rats (Schwab and Schnell, 1989). Further, Western blot studies have shown that MAG expression dramatically increases after P14 (Fujita et al., 1998; Cho et al., 2005). Our results on MAG expression are also consistent with those of the MAG mRNA expression reported previously (Jordan et al., 1989).

In present study, we used focal cortical injury model and focused on two corticofugal pathways, CRT and CST, originating from uninjured sensorimotor cortex. Previous studies have shown that significant bilateral innervations are induced by intact CRT and CST in cortical photothrombosis model (Lee et al., 2004) or focal cortical infarct model (Zai et al., 2009), and these midline-crossing axons sprouted from intact CRT and CST have shown to be highly correlated with functional recovery after cortical injury. In our model, although the CST in the injured side was completely broken down, CRT might be depredated only partially because previous retrograde tracing study shows that CRT neurons were found homogenously throughout greater extent of the large cortical area than those of CST (Akintunde and Buxton, 1992). Despite this incomplete injury of CRT, enhanced midline crossing CRT fibers have been demonstrated following focal cortical ischemia (Lee et al., 2004) and middle cerebral artery occlusion (Papadopoulos et al., 2002; Seymour et al., 2005).

While blocking PirB activity was found to reduce the myelinassociated inhibition of neurite outgrowth in cultured cerebellar neurons (Atwal et al., 2008), it is possible that PirB does not play a critical role in inhibiting axonal plasticity in the mouse cortical injury model. One reason for thinking this is our finding that PirB was expressed in only a subset of CNS neurons. While PirB was expressed partly in sensorimotor cortex neurons, only a small population of corticospinal neurons showed positivity for PirB (Fig. 3A-C). Moreover, immunostaining revealed that PirB expression was not observed in the adult spinal cord (Fig. $3 M$ ). We also have found that PirB expression in the adult mouse brain and spinal cord is too low to be detected by Western blotting without immunoprecipitation (data not shown).

PirB was originally identified as a receptor involved in pathways inhibiting the immune response (Takai and Ono, 2001). Consistent with this, it had been shown in $\mathrm{PirB}^{-/-}$mice that immune cells, including neutrophils and macrophages, are continuously hyperactive (Takai, 2005). It is possible that hyperactivated neutrophils or macrophages (blood-derived macrophages or resident microglia) exacerbate secondary tissue damage after a cortical lesion (Hailer, 2008; Jin et al., 2010). However, we did not observe an exacerbation of secondary damage, in terms of lesion volume, in PirB ${ }^{-1-}$ mice (Fig. $4 C$ ). There is currently insufficient information concerning immune responses after CNS lesions in $\mathrm{PirB}^{-1-}$ mice, and it remains unknown whether the genetic de- letion of PirB has effects on tissue damage or motor function after cortical injury.

\section{References}

Akintunde A, Buxton DF (1992) Origins and collateralization of corticospinal, corticopontine, corticorubral and corticostriatal tracts: a multiple retrograde fluorescent tracing study. Brain Res 586:208-218.

Atwal JK, Pinkston-Gosse J, Syken J, Stawicki S, Wu Y, Shatz C, TessierLavigne M (2008) PirB is a functional receptor for myelin inhibitors of axonal regeneration. Science 322:967-970.

Baird AL, Meldrum A, Dunnett SB (2001) The staircase test of skilled reaching in mice. Brain Res Bull 54:243-250.

Baskin YK, Dietrich WD, Green EJ (2003) Two effective behavioral tasks for evaluating sensorimotor dysfunction following traumatic brain injury in mice. J Neurosci Methods 129:87-93.

Benowitz LI, Carmichael ST (2010) Promoting axonal rewiring to improve outcome after stroke. Neurobiol Dis 37:259-266.

Benson MD, Romero MI, Lush ME, Lu QR, Henkemeyer M, Parada LF (2005) Ephrin-B3 is a myelin-based inhibitor of neurite outgrowth. Proc Natl Acad Sci U S A 102:10694-10699.

Bradbury EJ, Moon LD, Popat RJ, King VR, Bennett GS, Patel PN, Fawcett JW, McMahon SB (2002) Chondroitinase ABC promotes functional recovery after spinal cord injury. Nature 416:636-640.

Chen P, Goldberg DE, Kolb B, Lanser M, Benowitz LI (2002) Inosine induces axonal rewiring and improves behavioral outcome after stroke. Proc Natl Acad Sci U S A 99:9031-9036.

Cho KS, Yang L, Lu B, Feng Ma H, Huang X, Pekny M, Chen DF (2005) Re-establishing the regenerative potential of central nervous system axons in postnatal mice. J Cell Sci 118:863-872.

Domeniconi M, Cao Z, Spencer T, Sivasankaran R, Wang K, Nikulina E, Kimura N, Cai H, Deng K, Gao Y, He Z, Filbin M (2002) Myelinassociated glycoprotein interacts with the Nogo66 receptor to inhibit neurite outgrowth. Neuron 35:283-290.

Fournier AE, GrandPre T, Strittmatter SM (2001) Identification of a receptor mediating Nogo-66 inhibition of axonal regeneration. Nature 409:341-346

Fujita N, Kemper A, Dupree J, Nakayasu H, Bartsch U, Schachner M, Maeda N, Suzuki K, Popko B (1998) The cytoplasmic domain of the large myelin-associated glycoprotein isoform is needed for proper CNS but not peripheral nervous system myelination. J Neurosci 18:1970-1978.

Giger RJ, Venkatesh K, Chivatakarn O, Raiker SJ, Robak L, Hofer T, Lee H, Rader C (2008) Mechanisms of CNS myelin inhibition: evidence for distinct and neuronal cell type specific receptor systems. Restor Neurol Neurosci 26:97-115.

Goldshmit Y, Galea MP, Wise G, Bartlett PF, Turnley AM (2004) Axonal regeneration and lack of astrocytic gliosis in EphA4-deficient mice. J Neurosci 24:10064-10073.

GrandPré T, Li S, Strittmatter SM (2002) Nogo-66 receptor antagonist peptide promotes axonal regeneration. Nature 417:547-551.

Hailer NP (2008) Immunosuppression after traumatic or ischemic CNS damage: it is neuroprotective and illuminates the role of microglial cells. Prog Neurobiol 84:211-233.

Hata K, Fujitani M, Yasuda Y, Doya H, Saito T, Yamagishi S, Mueller BK, Yamashita $T$ (2006) RGMa inhibition promotes axonal growth and recovery after spinal cord injury. J Cell Biol 173:47-58.

Hu F, Strittmatter SM (2008) The N-terminal domain of Nogo-A inhibits cell adhesion and axonal outgrowth by an integrin-specific mechanism. J Neurosci 28:1262-1269.

Jin R, Yang G, Li G (2010) Inflammatory mechanisms in ischemic stroke: role of inflammatory cells. J Leukoc Biol 87:779-789.

Jordan C, Friedrich V Jr, Dubois-Dalcq M (1989) In situ hybridization analysis of myelin gene transcripts in developing mouse spinal cord. J Neurosci 9:248-257.

Kim JE, Liu BP, Park JH, Strittmatter SM (2004) Nogo-66 receptor prevents raphespinal and rubrospinal axon regeneration and limits functional recovery from spinal cord injury. Neuron 44:439-451.

Kuang RZ, Kalil K (1990) Specificity of corticospinal axon arbors sprouting into denervated contralateral spinal cord. J Comp Neurol 302:461-472.

Lee JK, Kim JE, Sivula M, Strittmatter SM (2004) Nogo receptor antagonism promotes stroke recovery by enhancing axonal plasticity. J Neurosci 24:6209-6217. 
Li S, Strittmatter SM (2003) Delayed systemic Nogo-66 receptor antagonist promotes recovery from spinal cord injury. J Neurosci 23:4219-4227.

Li S, Liu BP, Budel S, Li M, Ji B, Walus L, Li W, Jirik A, Rabacchi S, Choi E, Worley D, Sah DW, Pepinsky B, Lee D, Relton J, Strittmatter SM (2004) Blockade of Nogo-66, myelin-associated glycoprotein, and oligodendrocyte myelin glycoprotein by soluble Nogo-66 receptor promotes axonal sprouting and recovery after spinal injury. J Neurosci 24:10511-10520.

Li S, Kim JE, Budel S, Hampton TG, Strittmatter SM (2005) Transgenic inhibition of Nogo-66 receptor function allows axonal sprouting and improved locomotion after spinal injury. Mol Cell Neurosci 29:26-39.

Liu BP, Fournier A, GrandPré T, Strittmatter SM (2002) Myelin-associated glycoprotein as a functional ligand for the Nogo-66 receptor. Science 297:1190-1193.

Löw K, Culbertson M, Bradke F, Tessier-Lavigne M, Tuszynski MH (2008) Netrin-1 is a novel myelin-associated inhibitor to axon growth. J Neurosci 28:1099-1108.

Montoya CP, Campbell-Hope LJ, Pemberton KD, Dunnett SB (1991) The "staircase test": a measure of independent forelimb reaching and grasping abilities in rats. J Neurosci Methods 36:219-228.

Moreau-Fauvarque C, Kumanogoh A, Camand E, Jaillard C, Barbin G, Boquet I, Love C, Jones EY, Kikutani H, Lubetzki C, Dusart I, Chédotal A (2003) The transmembrane semaphorin Sema4D/CD100, an inhibitor of axonal growth, is expressed on oligodendrocytes and upregulated after CNS lesion. J Neurosci 23:9229-9239.

Murphy TH, Corbett D (2009) Plasticity during stroke recovery: from synapse to behaviour. Nat Rev Neurosci 10:861-872.

Nudo RJ (2006) Mechanisms for recovery of motor function following cortical damage. Curr Opin Neurobiol 16:638-644.

Ono K, Shimada M, Yamano T (1990) Reorganization of the corticospinal tract following neonatal unilateral cortical ablation in rats. Brain Dev 12:226-236.

Onyszchuk G, Al-Hafez B, He YY, Bilgen M, Berman NE, Brooks WM (2007) A mouse model of sensorimotor controlled cortical impact: characterization using longitudinal magnetic resonance imaging, behavioral assessments and histology. J Neurosci Methods 160:187-196.

Papadopoulos CM, Tsai SY, Alsbiei T, O’Brien TE, Schwab ME, Kartje GL (2002) Functional recovery and neuroanatomical plasticity following middle cerebral artery occlusion and IN-1 antibody treatment in the adult rat. Ann Neurol 51:433-441.

Pronichev IV, Lenkov DN (1998) Functional mapping of the motor cortex of the white mouse by a microstimulation method. Neurosci Behav Physiol 28:80-85.

Reinoso BS, Castro AJ (1989) A study of corticospinal remodelling using retrograde fluorescent tracers in rats. Exp Brain Res 74:387-394.

Schnaar RL, Lopez PH (2009) Myelin-associated glycoprotein and its axonal receptors. J Neurosci Res 87:3267-3276.

Schwab ME, Bartholdi D (1996) Degeneration and regeneration of axons in the lesioned spinal cord. Physiol Rev 76:319-370.

Schwab ME, Schnell L (1989) Region-specific appearance of myelin constituents in the developing rat spinal cord. J Neurocytol 18:161-169.

Seymour AB, Andrews EM, Tsai SY, Markus TM, Bollnow MR, Brenneman MM, O’Brien TE, Castro AJ, Schwab ME, Kartje GL (2005) Delayed treatment with monoclonal antibody IN-1 1 week after stroke results in recovery of function and corticorubral plasticity in adult rats. J Cereb Blood Flow Metab 25:1366-1375.

Starkey ML, Barritt AW, Yip PK, Davies M, Hamers FP, McMahon SB, Bradbury EJ (2005) Assessing behavioural function following a pyramidotomy lesion of the corticospinal tract in adult mice. Exp Neurol 195:524-539.

Sun F, He Z (2010) Neuronal intrinsic barriers for axon regeneration in the adult CNS. Curr Opin Neurobiol. Advance online publication. Retrieved April 23, 2010. doi:10.1016/j.conb.2010.03.013.

Syken J, Grandpre T, Kanold PO, Shatz CJ (2006) PirB restricts oculardominance plasticity in visual cortex. Science 313:1795-1800.

Takahashi M, Vattanajun A, Umeda T, Isa K, Isa T (2009) Large-scale reorganization of corticofugal fibers after neonatal hemidecortication for functional restoration of forelimb movements. Eur J Neurosci 30:18781887.

Takai T (2005) Paired immunoglobulin-like receptors and their MHC class I recognition. Immunology 115:433-440.

Takai T, Ono M (2001) Activating and inhibitory nature of the murine paired immunoglobulin-like receptor family. Immunol Rev 181:215-222.

Thallmair M, Metz GA, Z'Graggen WJ, Raineteau O, Kartje GL, Schwab ME (1998) Neurite growth inhibitors restrict plasticity and functional recovery following corticospinal tract lesions. Nat Neurosci 1:124-131.

Ujike A, Takeda K, Nakamura A, Ebihara S, Akiyama K, Takai T (2002) Impaired dendritic cell maturation and increased $\mathrm{T}(\mathrm{H}) 2$ responses in PIR-B(-/-) mice. Nat Immunol 3:542-548.

Vanek P, Thallmair M, Schwab ME, Kapfhammer JP (1998) Increased lesion-induced sprouting of corticospinal fibres in the myelin-free rat spinal cord. Eur J Neurosci 10:45-56.

Wang KC, Koprivica V, Kim JA, Sivasankaran R, Guo Y, Neve RL, He Z (2002) Oligodendrocyte-myelin glycoprotein is a Nogo receptor ligand that inhibits neurite outgrowth. Nature 417:941-944.

Wu C, Tian D, Feng Y, Polak P, Wei J, Sharp A, Stankoff B, Lubetzki C, Zalc B, Mufson EJ, Gould RM, Feinstein DL, Wang Y (2006) A novel fluorescent probe that is brain permeable and selectively binds to myelin. J Histochem Cytochem 54:997-1004.

Yamashita T, Fujitani M, Yamagishi S, Hata K, Mimura F (2005) Multiple signals regulate axon regeneration through the Nogo receptor complex. Mol Neurobiol 32:105-111.

Yiu G, He Z (2006) Glial inhibition of CNS axon regeneration. Nat Rev Neurosci 7:617-627.

Zai L, Ferrari C, Subbaiah S, Havton LA, Coppola G, Strittmatter S, Irwin N, Geschwind D, Benowitz LI (2009) Inosine alters gene expression and axonal projections in neurons contralateral to a cortical infarct and improves skilled use of the impaired limb. J Neurosci 29:8187-8197.

Zhang L, Schallert T, Zhang ZG, Jiang Q, Arniego P, Li Q, Lu M, Chopp M (2002) A test for detecting long-term sensorimotor dysfunction in the mouse after focal cerebral ischemia. J Neurosci Methods 117:207-214.

Zheng B, Atwal J, Ho C, Case L, He XL, Garcia KC, Steward O, TessierLavigne M (2005) Genetic deletion of the Nogo receptor does not reduce neurite inhibition in vitro or promote corticospinal tract regeneration in vivo. Proc Natl Acad Sci U S A 102:1205-1210. 